\title{
Avaliação Reológica de Elastômeros e suas Composições
}

\author{
Bianca B. Guerra \\ Petroflex Indústria e Comércio, RJ
}

\author{
Cristina R. G. Furtado, Fernanda M. B. Coutinho \\ Instituto de Química, UERJ
}

\begin{abstract}
Resumo: Os materiais elastoméricos apresentam tanto características de materiais sólidos como de líquidos, sendo assim considerados materiais viscoelásticos. Nas operações convencionais de processamento, esses materiais ficam sujeitos a vários tipos de deformações, devido à complexidade dos equipamentos. Esses materiais respondem à ação das deformações com um comportamento reológico viscoelástico, ou seja, uma combinação de respostas elásticas e viscosas. As propriedades viscoelásticas têm grande influência sobre o desempenho dos artefatos de borracha. Essas propriedades podem ser determinadas, permitindo assim, em alguns casos, o estabelecimento de uma relação com o comportamento dos materiais elastoméricos durante o seu processamento. Esta pequena revisão aborda com maior ênfase a utilização do Analisador de Processamento de Borracha-RPA (Rubber Process Analyzer) na determinação do comportamento reológico dos elastômeros. O RPA apresenta uma grande flexibilidade na realização de testes reológicos, pois permite a combinação de diferentes freqüências, deformações e temperaturas.
\end{abstract}

Palavras-chave: Elastômeros, reologia, composições elastoméricas, Analisador de Processamento de Borracha (RPA).

\section{Rheological Evaluation of Elastomers and their Compounds}

Abstract: Elastomers are viscoelastic materials; they combine solid and liquid characteristics. During processing operations, these materials are deformed in different ways and show a viscoelastic behavior. The viscoelastic properties have a powerful influence on the rubber products performance. These properties should be measured in order to predict, in some cases, the elastomers behavior during processing. This brief review gives more emphasis to the elastomer rheological characterization using the Rubber Process Analyzer (RPA).

Keywords: Elastomers, rheology, elastomer compounds, Rubber Process Analyzer (RPA).

\section{Introdução}

Reologia é a ciência que estuda o escoamento e a deformação da matéria sob a ação de uma força ou mais freqüentemente de um campo de forças ${ }^{[1,2]}$. Em outras palavras, é o estudo da resposta interna dos materiais quando da aplicação de diferentes forças ${ }^{[3]}$.

Quando uma pequena tensão é aplicada à um material sólido, uma deformação se inicia. O material irá continuar a se deformar até que as tensões moleculares (internas) se estabeleçam e se equilibrem com as tensões externas. A maioria dos sólidos exibe algum grau de resposta elástica, onde existe uma completa recuperação da deformação após a remoção das tensões de deformação. O material sólido mais simples é o sólido elástico de Hooke, cuja deformação é diretamente proporcional à tensão aplicada. A resposta elástica também pode ser exibida pelos materiais nãoHookeanos, cuja deformação não está linearmente relacionada à tensão aplicada ${ }^{[3]}$.

Nem todos os materiais atingem uma deformação de equilíbrio. Se uma tensão externa for aplicada a um fluido, a de- formação ocorre, e continua a ocorrer indefinidamente até que a tensão seja removida, pois o fluido não apresenta nenhuma resistência à deformação. As forças de fricção internas, ou seja, a viscosidade do fluido, retarda a taxa de deformação. Entretanto, um equilíbrio pode ser estabelecido onde a taxa de deformação é constante e relacionada com as propriedades do fluido. O mais simples destes fluidos é o Newtoniano, em que a taxa de deformação é diretamente proporcional à tensão aplicada. Existem vários tipos de fluidos que exibem uma resposta não-linear em relação à tensão aplicada e são denominados de fluidos não-Newtonianos ${ }^{[3]}$.

Entre os extremos de comportamento de sólido elástico ideal e de fluido viscoso ideal encontra-se um amplo espectro de materiais ${ }^{[1]}$. Os materiais poliméricos nos estados, sólido, fundido ou em solução, também apresentam este tipo de comportamento, já que ao serem submetidos à uma tensão de cisalhamento ou extensão, ocorre uma deformação instantânea, característica de um sólido elástico de Hooke, seguida de uma deformação contínua ou fluência (creep). Quando a tensão é removida, parte da deformação se recupera instantaneamente, outra parte se recupera com

Autor para correspondência: Fernanda M. B. Coutinho, Instituto de Química, UERJ, Rua São Francisco Xavier 524, Pav. Haroldo Lisboa da Cunha Maracanã, CEP: 20559-900, Rio de Janeiro, RJ. E-mail:fern@uerj.br 
o tempo e em alguns materiais ocorre uma deformação permanente. Esta resposta, que depende do tempo, é conhecida como viscoelasticidade e é inerente dos materiais de elevado peso molecular ${ }^{[1,4]}$.

Desse modo, durante o processamento dos polímeros, estes materiais sofrem diversos tipos de deformações em virtude da complexidade da geometria dos equipamentos utilizados, e respondem com um comportamento reológico viscoelástic $o^{[4]}$, resultado da sobreposição de pelo menos dois regimes reológicos simples: um fluxo de cisalhamento simples e um fluxo de estiramento ou alongamento simples. O primeiro produzido por forças de cisalhamento e o segundo produzido por forças de tração segundo uma única direção ${ }^{[2]}$.

Ao se visualizar os rotores de um misturador interno ou o parafuso de uma extrusora compreende-se facilmente que os caminhos tortuosos percorridos pelo material não podem ser tratados em termos de um cisalhamento simples. Mesmo ao isolar uma ou outra zona aparentemente elementar de escoamento em um equipamento de transformação, constata-se que a situação não é simples e resulta praticamente da combinação de dois ou mais regimes reológicos elementares ${ }^{[2]}$. Por exemplo, durante a extrusão, o polímero sofre cisalhamento no interior da extrusora e alongamento no início da matriz, o que provoca o aparecimento de tensões normais e conseqüentemente o fenômeno do inchamento do extrusado (die swell). Na moldagem por injeção também são observadas deformações de cisalhamento e alongamento em regime transiente no parafuso recíproco, além de cisalhamento elevado nos canais e cavidades dos moldes. Essas deformações podem provocar o aparecimento de tensões internas no moldado ou defeitos na peça. A morfologia e, conseqüentemente, as propriedades mecânicas desses materiais e de suas composições serão determinadas por estas deformações e tensões. Assim, torna-se necessário conhecer o comportamento desses materiais quando em situações de escoamento, para poder prever e compreender o desempenho do artefato final ${ }^{[4]}$.

As caracterizações reológicas realizadas em laboratório em elastômeros puros ou em composições não vulcanizadas baseiam-se na resistência desses materiais às forças aplicadas durante as operações de processamento. Em geral, torna-se necessário realizar inúmeros ensaios, de maneira a assegurar o processamento uniforme, a vulcanização perfeita e a obtenção de todas as propriedades necessárias no produto final ${ }^{[5]}$.

Os principais ensaios para a excelência do produto final estão relacionados com a processabilidade e com as características de vulcanização. O primeiro estabelece a quantidade de energia necessária para a mistura e a conformação do elastômero, enquanto o segundo define o tempo disponível para a realização destas operações.

\section{Processabilidade}

Os testes usados para definir plasticidade são classificados com base na taxa de cisalhamento, considerando que os diferentes processos utilizados para o processamento das borrachas envolvem diferentes níveis de cisalhamento e de taxa de cisalhamento. A plasticidade pode, então, ser avalia- da em equipamentos sob compressão, cisalhamento rotacional e extrusão ${ }^{[6]}$.

Os equipamentos que operam sob compressão fornecem uma taxa de cisalhamento baixa $\left(<0,1 \mathrm{~s}^{-1}\right)$ e foram os primeiros a serem desenvolvidos ${ }^{[6]}$. Dentre eles, destaca-se o plastômetro de placas paralelas que se baseia na medida da resistência do elastômero puro e/ou da composição não vulcanizada à compressão, por meio da medida da plasticidade e da recuperação. Neste caso, a plasticidade é obtida através da espessura em milímetros, multiplicada por 100, de uma amostra cilíndrica com aproximadamente $13 \mathrm{~mm}$ de diâmetro e cerca de $8,4 \mathrm{~mm}$ de altura, após ter sido submetida a uma força de compressão de $5 \mathrm{~kg}$, em tempo e temperatura determinados. A recuperação é a diferença em milímetros, multiplicada por 100 , entre a espessura da amostra ao ser retirada do plastômetro e após determinado tempo sob repouso. Os plastômetros de placas paralelas mais utilizados são o Williams e o Wallace ${ }^{[5]}$.

Um grande número de plastômetros de cisalhamento rotacional foi desenvolvido durante o rápido crescimento da indústria de borracha no período de 1920 a 1940. Entretanto o viscosímetro de disco cisalhante desenvolvido por Melvin Mooney, tornou-se o "padrão" da indústria de borracha $^{[6]}$. O viscosímetro Mooney determina a viscosidade do elastômero puro e/ou da composição não vulcanizada, em função da resistência ao cisalhamento ${ }^{[5]}$. O método que descreve a determinação da viscosidade Mooney é o ASTM D-1646.

Quanto maior for a viscosidade, menor a plasticidade do elastômero ou da composição. A viscosidade ${ }^{[5]}$ está intimamente ligada ao peso molecular do elastômero e é dada pela Equação 1.

$$
[\eta]=(P M)^{\mathrm{a}} \cdot \mathrm{K}
$$

onde: $[\eta]=$ viscosidade intrínseca; $(\mathrm{PM})=$ peso molecular médio do elastômero; $\mathrm{K}=$ constante que depende exclusivamente do elastômero; $\mathrm{a}=$ grau de enovelamento da molécula.

Os valores das constantes $\mathrm{K}$ e a são determinados experimentalmente. Assim, pode-se notar pela Equação 1 que, à medida que se aumenta o peso molecular médio, a viscosidade também aumenta ${ }^{[5]}$.

O Viscosímetro Mooney consiste essencialmente de um rotor de metal que gira a uma velocidade de $2 \mathrm{rpm}$, como indicado na Figura 1.

Existem dois rotores padrões para o teste de viscosidade Mooney: o rotor grande (L) com diâmetro de 1,5 $\pm 0,001 "$ (usado para polímeros e composições de baixa viscosidade) e o rotor pequeno (S) com diâmetro de 1,2 $\pm 0,001$ " (usado para polímeros e composições de alta viscosidade).

A temperatura do ensaio é normalmente de $100{ }^{\circ} \mathrm{C}$, porém outras temperaturas também podem ser usadas. $\mathrm{O}$ corpo-deprova consiste de duas partes do material a ser testado, com diâmetros e espessuras suficientes para preencher totalmente a cavidade do aparelho. As duas partes do corpo de prova envolvem o rotor de metal, que gira lenta e continuamente por determinado período de tempo. A resistência à rotação é 


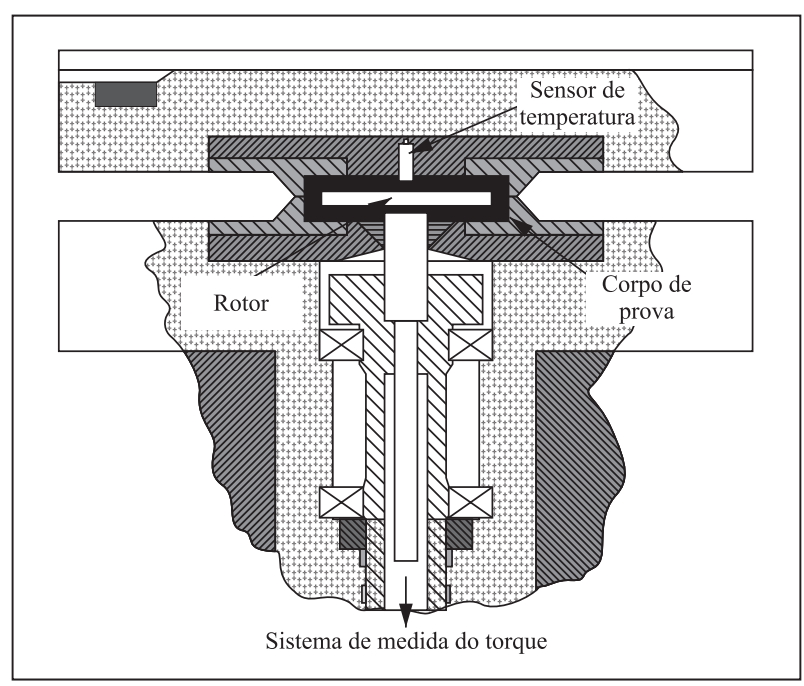

Figura 1. Esquema da cavidade de teste do viscosímetro Mooney ${ }^{[3]}$.

medida em unidades arbitrárias como viscosidade Mooney ${ }^{[5]}$ e é apresentada da seguinte forma, na Equação 2:

$$
50 \text {-ML } 1+4\left(100^{\circ} \mathrm{C}\right)
$$

onde:

50 - indica viscosidade (unidades);

$\mathrm{M}$ - indica Mooney;

L - indica o tipo do rotor usado (grande);

1 - indica o tempo de pré-aquecimento, em minutos

4 - indica o tempo do ensaio contado após a partida do rotor, em minutos

$\left(100{ }^{\circ} \mathrm{C}\right)$ - indica a temperatura do ensaio.

A avaliação do desempenho de uma composição elastomérica não-vulcanizada durante a extrusão pode ser realizada por meio do método padrão ASTM D2230 (extrusabilidade de Garvey), que utiliza uma extrusora de laboratório com características definidas na própria norma, equipada com uma matriz do tipo Garvey. Este método permite, pela perfeição do perfil extrusado, que se avalie de maneira subjetiva a extrusabilidade do material.

Uma medida mais quantitativa das características de extrusão pode ser obtida pelo equipamento de Pliskin ${ }^{[7]}$. Este teste envolve o cálculo do inchamento do extrusado (die swell), razão entre a seção transversal do extrusado e a seção transversal da matriz, por meio da medida da velocidade da corrente do extrusado oriundo da matriz em um volume constante de extrusão. A proporcionalidade existente entre o inchamento do extrusado e a velocidade assume que este fenômeno, resultante da memória elástica do material, ocorre quase que instantaneamente após a saída da composição da matriz.

Outros equipamentos com detectores automáticos de inchamento de extrusado podem ser montados sobre reômetros capilares ${ }^{[8]}$. Os reômetros capilares foram desenvolvidos para medir propriedades reológicas básicas de líquidos e polímeros fundidos e, somente em 1970, a reologia capilar passou a ser usada para modelar processos de extrusão de composições elastoméricas $^{[6]}$.
Atualmente, alguns reômetros capilares existentes no mercado permitem a determinação da viscosidade, do inchamento do extrusado e da relaxação de tensão separadamente ou em uma seqüência de teste programável, em menos de cinco minutos ${ }^{[8]}$.

\section{Características de vulcanização (Reometria)}

O processo de vulcanização consiste em unir quimicamente as cadeias poliméricas individuais, por meio das ligações cruzadas, visando à obtenção de uma rede tridimensional elástica que irá exibir as propriedades elastoméricas desejadas no produto final. O desempenho do material nesta fase do processo é avaliado pelos testes de vulcanização. Embora este processo seja basicamente de natureza química, os testes usados são geralmente baseados em mudanças físicas que ocorrem na borracha ${ }^{[6]}$. Estas mudanças geralmente ocorrem em três estágios: período de indução; estágio de cura ou vulcanização; e estágio de reversão ou sobrecura.

O período de indução representa o tempo, na temperatura de vulcanização, durante o qual não ocorre formação das ligações cruzadas. Após o período de indução, ocorre a formação das ligações cruzadas em uma velocidade dependente da temperatura, do tipo de borracha e do sistema de cura empregado. À medida que os aditivos do sistema de cura são consumidos, as reações de vulcanização tornam-se lentas até que uma rigidez ótima é atingida. Este ponto representa a vulcanização completa. Aquecimento adicional pode resultar em um aumento muito lento da rigidez ou em seu decréscimo, dependendo do tipo de borracha utilizado. Estas mudanças finais são conhecidas como sobrecura ${ }^{[6]}$.

Atualmente, medidas das características de cura têm sido realizadas usando curômetros. Existem basicamente dois tipos de curômetros em uso ${ }^{[5]}$ : o reômetro de disco oscilatório (ODR) e o reômetro sem rotor ou de cavidade oscilante (MDR), conforme mostra a Figura 2.

$\mathrm{O}$ reômetro consiste essencialmente de 2 pratos, que são aquecidos, e de um registrador de torque versus tempo. A amostra é colocada em uma cavidade termicamente regulada (à temperatura de vulcanização escolhida) e a resistência oferecida (torque) pelo composto de borracha a uma oscilação de baixa amplitude $\left(0,5^{\circ}\right.$ para o MDR e 1,3 ou $5^{\circ}$ para o ODR) de um rotor bicônico (ODR) ou de uma meia-cavidade (MDR), é medida em função do tempo ${ }^{[5]}$, de acordo com as normas ASTM D2084 e ASTM D5289. A curva resultante é mostrada na Figura 3.

Entre os parâmetros determinados estão:

Torque mínimo $\left(\mathrm{M}_{\mathrm{L}}\right)$, que reflete razoavelmente a viscosidade de uma composição à temperatura de vulcanização considerada;

Tempo de pré-vulcanização (scorch time) $\left(\mathrm{t}_{\mathrm{sx}}\right)$, que é o tempo necessário para aumentar o torque mínimo de $2 \mathrm{lbf}$.in quando se usa o $\operatorname{arco} \pm 3^{\circ}$ ou $\pm 5^{\circ}$, ou de $1 \mathrm{lbf}$.in quando se usa $\mathrm{o} \operatorname{arco} \pm 1^{\circ}$. Essa propriedade é de grande importância, especialmente nos casos de misturas destinadas à extrusão e calandragem, pois indica o grau de segurança do processo; 


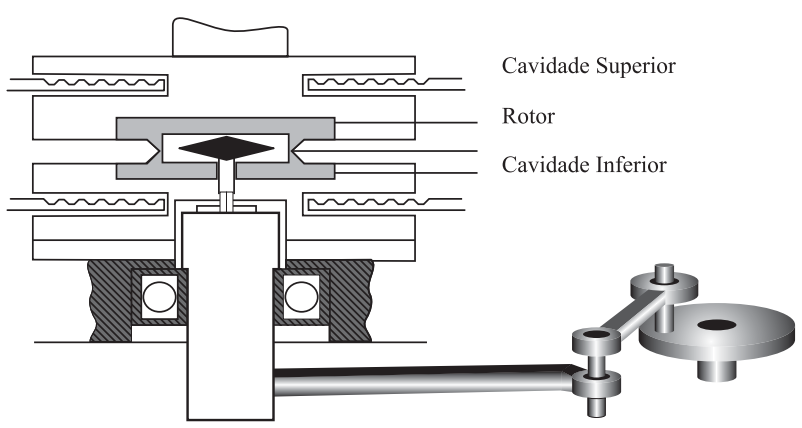

(a) reômetro tipo ODR

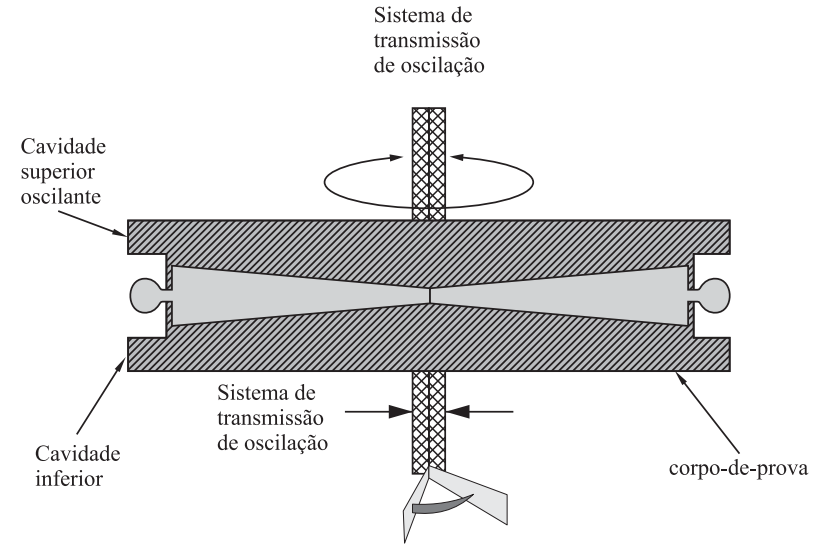

(b) reômetro tipo MDR

Figura 2. Esquema da cavidade de teste dos reômetros ${ }^{[5]}$. (a) tipo ODR; (b) tipo MDR.

Torque máximo $\left(\mathrm{M}_{\mathrm{H}}\right)$, que reflete razoavelmente o módulo do vulcanizado; e

$t_{90}$, também chamado de tempo ótimo de vulcanização, que é o tempo necessário para atingir $90 \%$ do torque máximo, obtido pela Equação 3.

$\mathrm{t}_{90}=\left(\mathrm{M}_{\mathrm{H}}-\mathrm{M}_{\mathrm{L}}\right) \times 0,9+\mathrm{M}_{\mathrm{L}}$

Com o reômetro do tipo MDR pode-se medir, simultaneamente, a componente viscosa (G”) e a componente elástica $\left(G^{\prime}\right)$ da composição elastomérica.

Atualmente, já está disponível no mercado uma nova

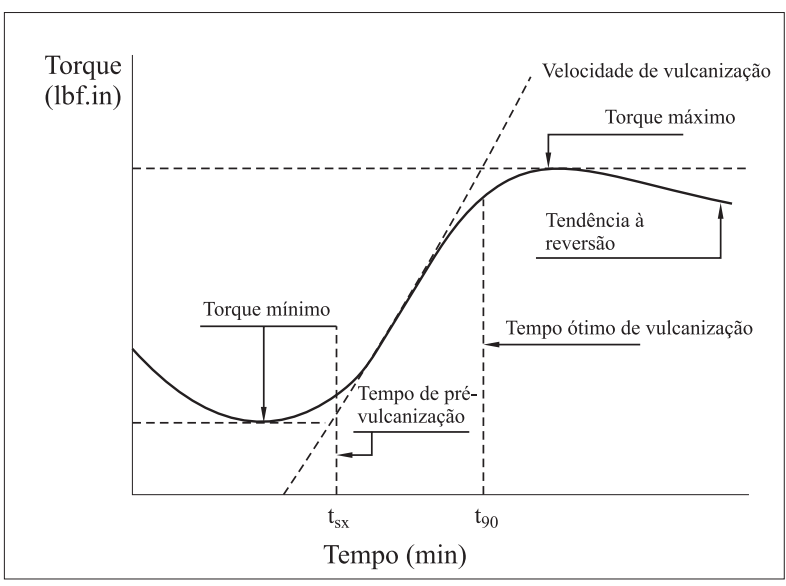

Figura 3. Gráfico torque versus tempo ${ }^{[5]}$. geração de reômetros sem rotor, destinados a testes reológicodinâmico-mecânicos (DMTR), que permite a variação ampla de temperaturas, deformações e freqüências, o RPA 2000 (Analisador de Processamento de Borracha).

\section{Analisador de Processamento de Borracha}

O Analisador de Processamento de Borracha, RPA 2000, desenvolvido pela Monsanto Instruments, e atualmente, fabricado e comercializado pela Alpha Technologies é um reômetro dinâmico torsional, cujo projeto da cavidade de teste é similar ao reômetro de cavidade oscilante (MDR), um bem conhecido curômetro sem rotor.

O RPA é um aparelho de teste reológico mecânico dinâmico (DMRT) com uma câmara de teste selada, que facilita, assim, o carregamento das amostras de borracha e permite a realização de testes em uma ampla faixa de ângulos de deformação $\left( \pm 0,05^{\circ} \mathrm{a} \pm 90^{\circ}\right)$ e freqüências $(0,1 \mathrm{a} 2000 \mathrm{cpm})$ normalmente maior do que a permitida nos outros DMRT's. A temperatura pode ser variada de modo a reproduzir melhor, as condições de processamento e/ou aplicações do produto final. Apesar do seu nome comercial, Analisador de Processamento de Borracha, o RPA foi projetado para medir as propriedades de polímeros crus, composições não curadas e curadas ${ }^{[9,10]}$.

A cavidade de amostra do RPA é constituída por dois blocos em formato cônico, com ranhuras para segurar a amostra, evitando, assim, o seu deslizamento. Os blocos são circundados por anéis de vedação que promovem a selagem na cavidade do teste. Existem ainda placas (de vedação) que cercam esses anéis, impedindo o escoamento da amostra ${ }^{[9]}$. A câmara de teste do RPA está esquematizada na Figura 4.

Como a cavidade de teste é selada, o RPA fornece boa repetibilidade e reprodutibilidade, sob tensões muito elevadas. Os demais DMRT's não possuem câmaras de amostra pressurizadas e seladas. Desse modo, o material na borda da cavidade não selada pode apresentar distorção sob tensões elevadas, de maneira não repetitiva, resultando em baixo desempenho ${ }^{[11,12]}$.

Outra vantagem da cavidade de teste do RPA é que a colocação da amostra é muito mais fácil do que nos DMRT's convencionais, que requerem uma preparação mais elaborada da amostra. A maioria dos DMRT's necessita de um ajuste cuidadoso durante a separação das placas ou blocos para assegurar que a amostra esteja em contato com os dois blocos. No RPA, a amostra é simplesmente colocada no centro do bloco inferior e o excesso de amostra é expelido para fora da cavidade ${ }^{[12]}$.

A forma da amostra provoca um efeito mínimo nos resultados dos testes e a maioria das amostras é removida facilmente da cavidade, mesmo quando não vulcanizada. Entretanto, deve-se controlar a quantidade da amostra (e sua densidade) a ser colocada na matriz. Esta não deve ser menor que o volume da cavidade, nem deve estar em grande excesso. O volume da amostra deve ficar entre 4,0 a $6,0 \mathrm{~cm}^{3}$.

Quando se testa materiais com alta aderência, filmes podem ser usados. Filmes de nylon ou poliéster são os mais utilizados, sendo o filme de nylon o mais apropriado, devido a sua maior flexibilidade, permitindo, assim, um maior alongamento. $\mathrm{O}$ 


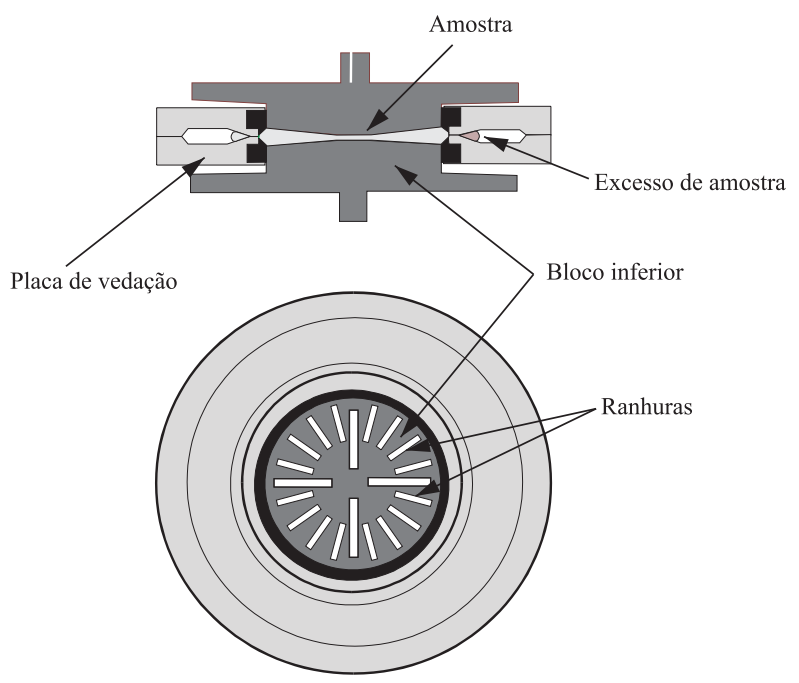

Figura 4. Cavidade de teste do RPA ${ }^{[9]}$

filme não deve ser usado em testes realizados sob ângulos de deformação superiores a $\pm 10^{\circ}( \pm 140 \%)$ porque pode sofrer rasgamento, alterando os resultados ${ }^{[11]}$.

Os blocos do RPA são aquecidos pelo contato direto com um aquecedor e resfriados por meio de um sistema de ar comprimido. O sistema de controle de temperatura dos dois blocos é independente e responde rapidamente às variações de temperatura. Os blocos podem ser aquecidos e resfriados ${ }^{[11]}$ a uma velocidade máxima de $1{ }^{\circ} \mathrm{C} /$ segundo e a temperatura pode ser ajustada para valores entre 40 e $230^{\circ} \mathrm{C}$.

A freqüência de oscilação pode ser ajustada de 0,1 a 2000 cpm $(0,00166$ a $33,3 \mathrm{~Hz})$. A magnitude do movimento do bloco inferior é regulada para um ângulo de deformação capaz de gerar a tensão na amostra. O bloco inferior pode oscilar de $\pm 0,05^{\circ} \mathrm{a} \pm 90^{\circ}$, que corresponde a uma deformação de $\pm 0,7 \%$ a $\pm 1256 \%$, respectivamente ${ }^{[12]}$.

As combinações de freqüência e ângulo de oscilação são limitadas ${ }^{[11]}$. O produto máximo entre a freqüência (cpm) e o ângulo de deformação $\left({ }^{\circ}\right)$ deve ser de 2,047 . Este valor equivale a uma taxa de cisalhamento de $30 \mathrm{~s}^{-1}$, conforme indicado na Tabela 1.

Uma vez com a amostra e fechado, o bloco inferior da cavidade do RPA oscila sob freqüência e deformação controlados. O torque é medido no bloco superior ${ }^{[11]}$, conforme mostra a Figura 5.

Nos testes dinâmicos, uma deformação harmônica senoidal (ou seja, o sinal de entrada) é aplicada e, desde que o material viscoelástico testado responda de maneira linear, o torque registrado (ou seja, o sinal de saída) é também senoidal, mas fora de fase por um ângulo $\delta$, dependendo do caráter viscoso do material testado ${ }^{[9,11]}$ (Figura 6).

No RPA, o ângulo de fase não é medido, de fato, mas é assumido que a deformação senoidal produz uma resposta de torque senoidal, apenas se o material testado fornece uma resposta viscoelástica linear, nas condições de teste selecionadas. O sinal de torque complexo $S^{*}(t, \omega)$ é inicialmente tratado de maneira que durante um ciclo, muitos valores discretos são lidos em períodos iguais na escala de tempo. Para qualquer torque
Tabela 1: Combinações de freqüência e deformação ${ }^{[11]}$

\begin{tabular}{cc}
\hline $\begin{array}{c}\text { Freqüiência } \\
(\mathbf{c p m})\end{array}$ & $\begin{array}{c}\text { Ângulo de deformação } \\
\left({ }^{\mathbf{(}}\right)\end{array}$ \\
\hline$<20$ & 90 \\
$20-50$ & 45 \\
$50-100$ & 10 \\
$100-500$ & 3 \\
\hline $500-2000$ & 1 \\
\hline Aquecedor & Bloco superior \\
\hline & Bloco inferior oscilante \\
\hline \hline Aquecedor & Th \\
\hline
\end{tabular}

Figura 5. Cavidade do teste do RPA ${ }^{[1]}$

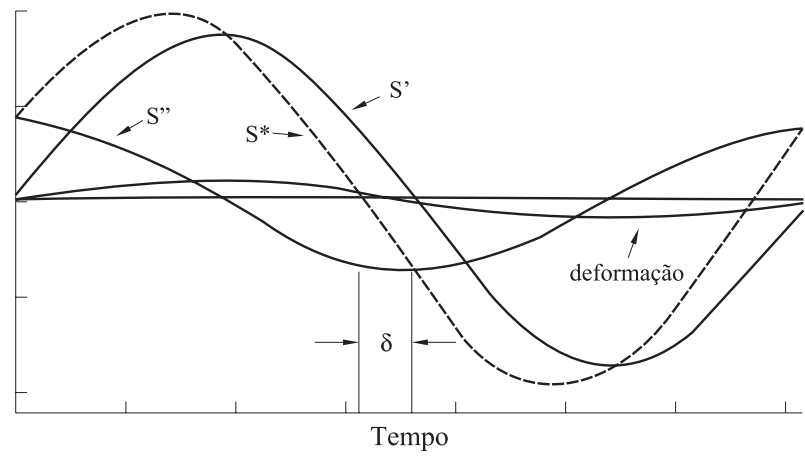

Figura 6. Deformação aplicada e respostas elástica, viscosa e complexa ${ }^{[11]}$

complexo (senoidal), tem-se a Equação 4:

$$
\mathrm{S}(\mathrm{t}, \omega)=\mathrm{S}^{*} \operatorname{sen}(\mathrm{t}, \omega+\delta)=\mathrm{S}^{\prime} \operatorname{sen}(\omega \mathrm{t})+\mathrm{S}^{\prime \prime} \cos (\omega \mathrm{t})
$$

e por meio de transformada de Fourier discreta, os valores selecionados de $\mathrm{S}(\mathrm{t})$ são usados para calcular o torque elástico S' (em fase com a deformação aplicada), o torque viscoso $\mathrm{S}^{\prime \prime}$ (defasado de $90^{\circ}$ em relação à deformação aplicada) e o ângulo de fase $\delta$, por meio das seguintes relações:

$$
\begin{gathered}
\mathrm{S}^{*}=\sqrt{\left(\mathrm{S}^{\prime 2}+\mathrm{S}^{\prime 2}\right)} \\
\delta=\tan ^{-1} \mathrm{~S}^{\prime \prime} / \mathrm{S}^{\prime}
\end{gathered}
$$

Os módulos de cisalhamento dinâmicos são obtidos usando o fator de forma para a cavidade de teste considerada $\left(B=\left(2 \pi R^{3}\right) / 3 \alpha\right)$, onde $R$ e $\alpha$ são respectivamente, o raio da cavidade $(20,625 \mathrm{~mm})$ e o ângulo entre os dois blocos cônicos $(0,125 \mathrm{rad})$; e as seguintes relações:

$$
\begin{aligned}
& \mathrm{G}^{*}=\mathrm{S}^{*} / \mathrm{B} \gamma \\
& \mathrm{G}^{\prime}=\left(\mathrm{S}^{*} \cos \delta\right) / \mathrm{B} \gamma \\
& \mathrm{G}^{\prime \prime}=\left(\mathrm{S}^{*} \operatorname{sen} \delta\right) / \mathrm{B} \gamma
\end{aligned}
$$


onde:

$\mathrm{G}^{*}$ - módulo complexo

$\mathrm{G}^{\prime}$ - módulo de armazenamento

G" - módulo de perda

$\gamma$ - ângulo da deformação aplicada

Além dos dados descritos acima, o RPA também fornece a viscosidade dinâmica real ( $\eta$ '), a viscosidade dinâmica complexa $\left(\eta^{*}\right)$, a compliância $(\mathrm{J})$ e outras informações ${ }^{[11,12]}$.

O RPA pode executar muitos tipos de sub-testes diferentes, que formam uma seqüência de grande flexibilidade. Estes sub-testes incluem:

- Testes de cura e tempo: Freqüência, deformação e temperatura são fixadas. O equipamento determina os torques $S^{\prime}$ e S" continuamente durante o tempo do teste e também calcula os torques mínimo e máximo, o tempo de pré-cura (scorch time) e o tempo de vulcanização.

- Varredura de freqüência: Deformação e temperatura permanecem constantes, enquanto a freqüência varia em uma maneira pré-programada.

- Varredura de deformação: Freqüência e temperatura permanecem constantes, enquanto a deformação varia em uma maneira pré-programada.

- Varredura de temperatura: Freqüência e deformação permanecem constantes, enquanto a temperatura varia em uma maneira pré-programada.

- Relaxação de tensão: O instrumento mede a relaxação do torque após uma etapa de deformação.

O RPA é rotineiramente usado no controle de qualidade de elastômeros sintéticos ${ }^{[12]}$. Por exemplo, o RPA consegue distinguir amostras que apresentam a mesma viscosidade Mooney, porém com valores de $\tan \delta$ muito diferentes.

O RPA também é usado na avaliação do desempenho e do processamento de diferentes composições. Por meio do acompanhamento do módulo de cisalhamento elástico $\left(\mathrm{G}^{\prime}\right)$, é possível avaliar a influência que a quantidade de carga e óleo tem sobre o processamento de uma composição de borracha. Além disso, o efeito da ordem de adição de óleo durante o processamento também pode ser avaliado, não só por meio do módulo elástico, mas também pelo módulo de cisalhamento viscoso $\left(G^{\prime \prime}\right)^{[13]}$.

O RPA não só é capaz de avaliar as propriedades medidas por um curômetro, como tempo de pré-vulcanização e velocidade de cura, mas possui a capacidade de realizar testes de degradação térmica e medir as alterações das propriedades dinâmicas de elastômeros crus ou de composições ${ }^{[13]}$.

O RPA também permite avaliar o desenvolvimento de calor durante o processamento de uma composição ${ }^{[14]}$.

\section{Conclusões}

O estudo da reologia é de extrema importância no campo da tecnologia dos polímeros, pois permite um maior entendimento de um grande número de falhas e defeitos que ocorrem durante o processamento desses materiais. Existem diversos equipamentos, como o viscosímetro Mooney, os reômetros e os plastômetros, que permitem a determinação das propriedades reológicas. $\mathrm{O}$ analisador de processamento de borracha (RPA) é um aparelho de teste reológico mecânico dinâmico (DMRT), que apresenta vantagens em relação aos demais equipamentos utilizados em reologia. O RPA pode analisar polímeros, elastômeros crus ou suas composições, tanto não vulcanizados quanto vulcanizados. A quantidade de amostra necessária para o teste é pequena e sua forma não influencia os resultados. Esse equipamento possui uma cavidade selada e pressurizada que permite a realização de testes em uma ampla faixa de ângulos de deformação e freqüências. O RPA apresenta uma grande flexibilidade na realização de testes, permitindo a combinação de diferentes freqüências, deformações e temperaturas. Além disso, possibilita a realização de testes de envelhecimento e de desenvolvimento de calor e mede tanto as propriedades elásticas como as viscosas de elastômeros.

\section{Agradecimentos}

CNPq, FAPERJ e Petroflex Indústria e Comércio S.A.

\section{Referências Bibliográficas}

1. Macosko, C. W. - "Rheology Principles, Measurements and Applications”, Wiley-VCH, New York (1994).

2. Leblanc, J. L. - "Rhéologie des Élastomères et Mise en Oeuvre des Polymères", Artel, Belgique (1996).

3. Cheremisinoff, N. P. - "An Introduction to Polymer Rheology and Processing”, CRC Press, Boca Raton (1993).

4. Bretas, R. E. S. \& D'Avila, M. A. - "Reologia de Polímeros Fundidos”, Editora da UFSCar, São Paulo (2000).

5. Rocha, E. C.; Lovison, V. M. H. \& Pierozan N. J. - "Tecnologia de Transformação dos Elastômeros", Centro Tecnológico de Polímeros SENAI - CETEPO, São Leopoldo (2003).

6. Morton, M. - "Rubber Technology", Van Nostrand Reinhold, New York (1987).

7. Pliskin, I. - Rubber Chem. Technol., 46, p.1218 (1973).

8. Bhowmick, A. K.; Hall, M. M. \& Benarey, H. A. - "Rubber Products Manufacturing Technology", Marcel Dekker, New York (1994).

9. Leblanc, J. L. \& Mongruel, A. - Progress in Rubber and Plastics Technol., 17(3), p.162 (2001).

10. Guerra, B. B. - Borracha Atual, no 41, p. 8 (2002).

11. Manual de Operação do RPA, Alpha Technologies (2003)

12. Cousins, W. \& Dick, J. S. - Rubber World, janeiro, p. 28 (1998).

13. Dick, J. S. \& Pawlowski, H. A. - “Applications for the Rubber Process Analyser", apresentado na Reunião da Divisão de Borracha ACS, Tennessee, Novembro (1992).

14. Dick, J. S.; Pawlowski, H. A. \& Moore, J. - "Viscous Heating and Reinforcement Effects using the Rubber Process Analyser", apresentado na Reunião da Divisão de Borracha ACS, Chicago, Abril (1999).

Enviado: $28 / 06 / 04$

Aprovado: 02/09/04 